\title{
CONSTRUCTION PROCESS SIMULATION IN BRIDGE BUILDING BASED ON SIGNIFICANT DAY-TO-DAY DATA
}

\author{
Karin Ailland \\ Hans-Joachim Bargstädt \\ Sebastian Hollermann \\ Bauhaus-University \\ Marienstraße 7A \\ D- 99423 Weimar, GERMANY
}

\begin{abstract}
Everyday life on bridge construction sites is commonly characterized by enormous pressure due to time and costs as well as difficult logistic requirements. Modern process simulation tools can be applied with increasing success. Projects are often affected by unscheduled constraints and limitations, that give reason to deviate from the formerly optimized plan, and to find ad-hoc solutions, especially in the erection phase. In order to meet these requirements, simulation tools in the erection phase with a more specific database are needed. An approach based on accurate day-to-day data for the current project state at any time is needed. These data then facilitate the simulation of possible variations for ongoing optimization. At first, it is necessary to determine, which choice of data is significant and actually needed for evaluating the day-to-day status in bridge construction progress. Secondly, the required data must be captured as efficiently as possible during the ongoing working activities.
\end{abstract}

\section{INTRODUCTION}

Non-stationary construction processes are commonly characterized by a great number of unexpected incidents and changing boundary conditions as well as by enormous time and cost pressure. In order to ensure the efficient use of valuable resources in spite of these challenges, a scheduling technique is needed that allows for active control and steering. Planning methods that feature adequate adaptability and support the description of parallel processes, unexpected incidents, and stochastic and fuzzy parameters are therefore necessary (Hohmann 1997).

Thus, modern simulation tools can be applied with increasing success. Up to now, these tools for the optimization of construction and logistical processes are predominantly used in the start-up phase of a project. Projects are often affected by unscheduled constraints and limitations, especially in the erection phase, that give reason to deviate from the formerly optimized plan and to find new current solutions.

The concept presented in this paper was developed with particular attention to time control. Experience in this field demonstrates that bar diagrams are still the predominant tools on most construction sites. Even critical path methods are uncommon. Simulations however, can provide much more information, such as the machine's productivity, possible hidden capacities, and reasons for reduced output (Hohmann 1997).

In order to meet the aforementioned requirements of daily construction business, the application of simulation tools could be extended from the planning phase to the erection phase. A more specific and dynamic data base is needed to effectively address this challenge. 


\section{Ailland, Bargstädt and Hollermann}

\section{SIMULATION}

Most research approaches that deal with process modeling in construction management strive for the support of decision-making processes. Therefore, linear and nonlinear optimization models that implicate relevant influences and boundary conditions are used. In addition to these, simulation tools are used more and more intensively for decision-making. Even if the results do not yield the overall optimum, they provide appropriate solutions for complex problems. The use of simulation tools is increasingly attractive as processes become more complex with multiple influences that must be considered. In simulation the mathematical complexity can be kept at a lower level compared to the mathematical linear and nonlinear optimization (Tecnomatix 2006).

Other branches of industry such as automobile (Bayer 2003) or shipbuilding (Beißert et al. 2007) already use simulation with great success. Examples include the planning of assembly lines and logistical processes.

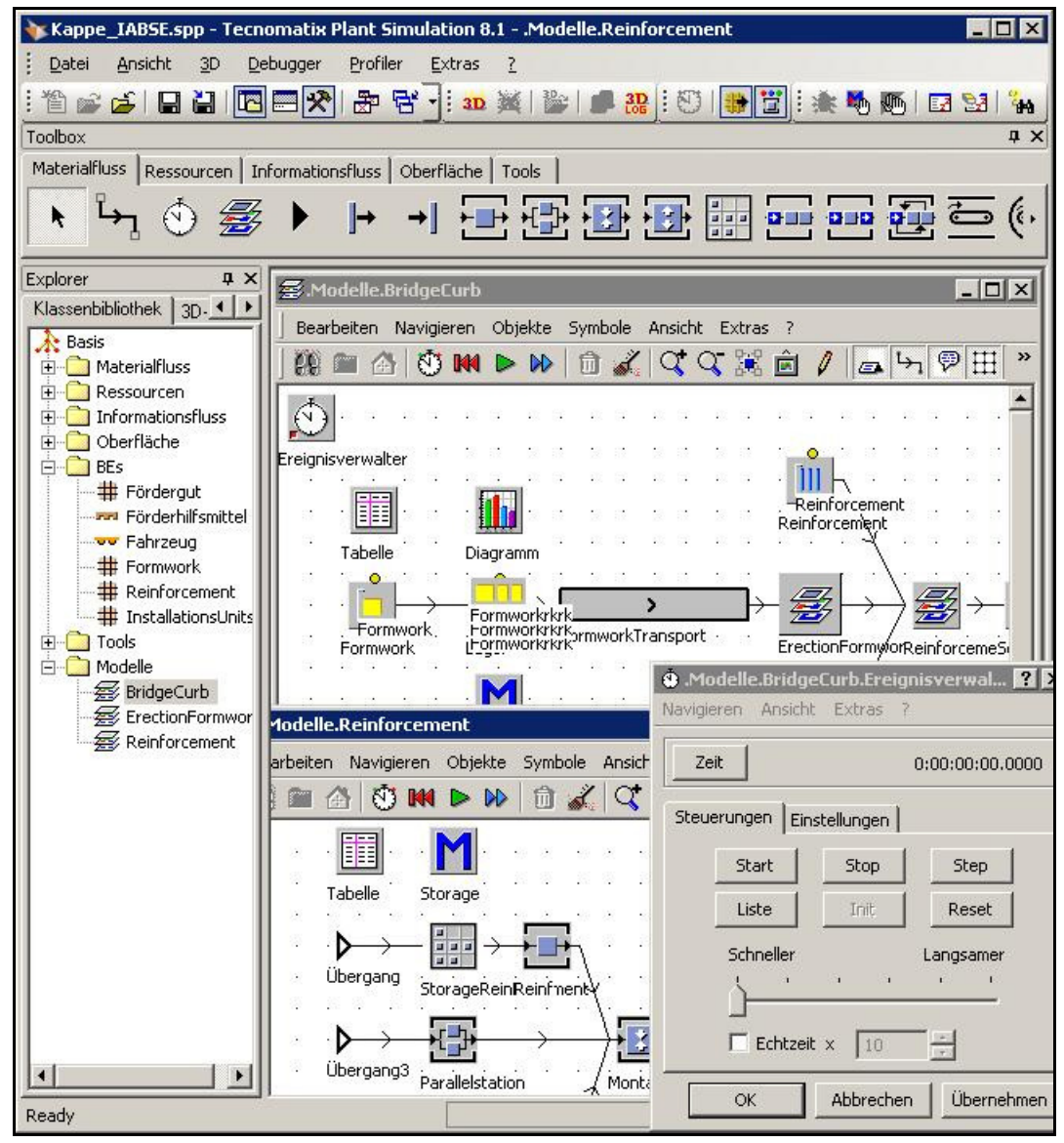

Figure 1: Simulation Tool

Methods used in these related areas must now be transferred from stationary industries to the building industry. The building industry is distinguished by individual products that vary in construction type, size, function, material and many more attributes. Moreover the construction conditions change with every new project as well as within the execution phases of the project. And within a construction site the working places change and move as the construction process progresses.

The authors use event-based simulation (Figure 1), as in Tecnomatix plant simulation (Tecnomatix 2006), which is already successfully utilized in stationary industry. 


\section{DESCRIPTION OF ON-SITE STATUS}

The optimization of processes by using simulation tools is more and more gaining importance in building industry. Therefore But important are reliable input data, because optimization results are only as strong as their experienced data base is.

Two aspects have to be captured for the construction process simulation and to be described in the simulation environment:

1.) data that define the construction process exactly, such as process times, dependencies, resources required etc. Based on accurate process times, the logical link between the process steps and the consideration of all relevant boundary conditions will create reasonable optimization results.

2.) data that define the environment in which the process runs, and capture information describing the current progress of construction and the construction site conditions, such as material inventory, human resources and describe the progress of the project in itself.

The Bauhaus-University Weimar works on the implementation of a reactive building process in simulation. This is designed to optimize the building process not only in the start up phase of the construction project, but also in the execution phase, when the site conditions are frequently changing. For this reason, the construction progress has to be determined at defined time intervals and data processing must be automated, thus enabling a further optimization of the construction process in the light of current conditions.

With regard to time controlling a method will be developed that represents the building progress on an accurate daily basis by identifying single process steps. This method will be sufficient for time controlling and more cost efficient than methods that capture geometric data, because there is less need for expensive technologies and analysis will be less time consuming. But the answer to the question "Which data do we really need?" is going to be a little complicated.

One aspect in this context is time controlling. Therefore we need reliable information about degrees of completion and the times of erection - more detailed information about the processes respectively sub processes of the project. There are different ways to describe the building progress. For example many research projects draw conclusions from the geometry, by analyzing image data or scatter plots.

Another area is the financial progress. For example today's reporting system is predominantly set up for capturing all information needed for cost controlling. The total budget and liquidity off a construction site are connected to the processes on site. The presented method starts from a process model that represents all process steps, dependencies and supporting documents, as delivery notes, proof or acceptance certificates. As example the curb of a bridge is chosen, because it represents a typical self-contained element of reinforced concrete construction, which is a typical hybrid construction element with several working steps and different involved personnel. Therefore the examination results will be transferable to other construction processes. That opens a great variety of prospect, also reinforced concrete is one of the most used building materials. But these information provide only a blurred image of the current status. Since the density of information for the simulation is not sufficient, the data from the construction site documentation is to be completed by the use of specific measurement. 


\subsection{Building process}

The process of constructing bridge curbs is not thoroughly described in the literature. Therefore the building process of several bridges was monitored, captured in detail, and documented. Different road bridges with varying degrees of complexity and different constraints were selected. In the following section, one of these projects is described in detail.

The largest of all monitored bridges is a $445 \mathrm{~m}$ long highway bridge in Germany with 12 spans and a double-webbed t-beam cross-section made of pre-stressed concrete. This bridge was built with a mobile scaffold. The formwork for the curb was on the ground bridge slab (Figure 2).

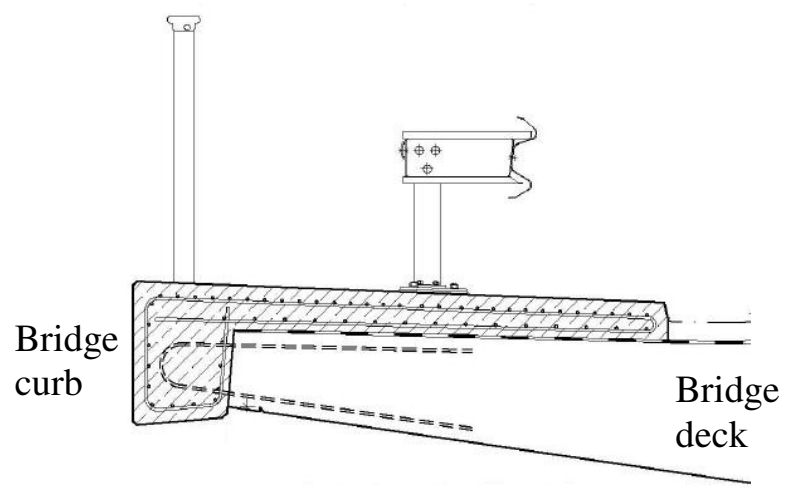

Figure 2: Bridge curb (Bundesministerium 2004)

This bridge shows multifaceted boundary conditions that strongly influence the building process and methods as well as the time scheduling. It bridges two farm tracks, an interstate highway, a highly frequented main railroad line and a river. All disturbances, including blocking the railroad track, had to be kept to a minimum. The river is part of a drinking water protection area and this causes strict environmental regulations.

Right from the beginning of the execution the construction sequence deviated and had to be rescheduled several times by the site manager. The ongoing management of the building progress was based on the site manager's competence alone. He had to act on a day-to-day basis. An efficient consideration of long-term consequences was almost impossible.

Within the monitoring of the real process, all interferences and the following deviations as well as the corrective activities were documented in order to use them for the presented approach, as well as for future simulation scenarios. Furthermore, the duration of all activities, as well as the exact need for material, machine, and manpower was monitored.

Other bridges were also monitored in this way in order to get a reliable data source. Based on these data a universally valid and conventionalized construction process for bridge curbs was designed. Event-driven process chains (EPC) were used to analyze and visualize all dependencies within the building process, because of their easy application and transparency (Figure 3). 

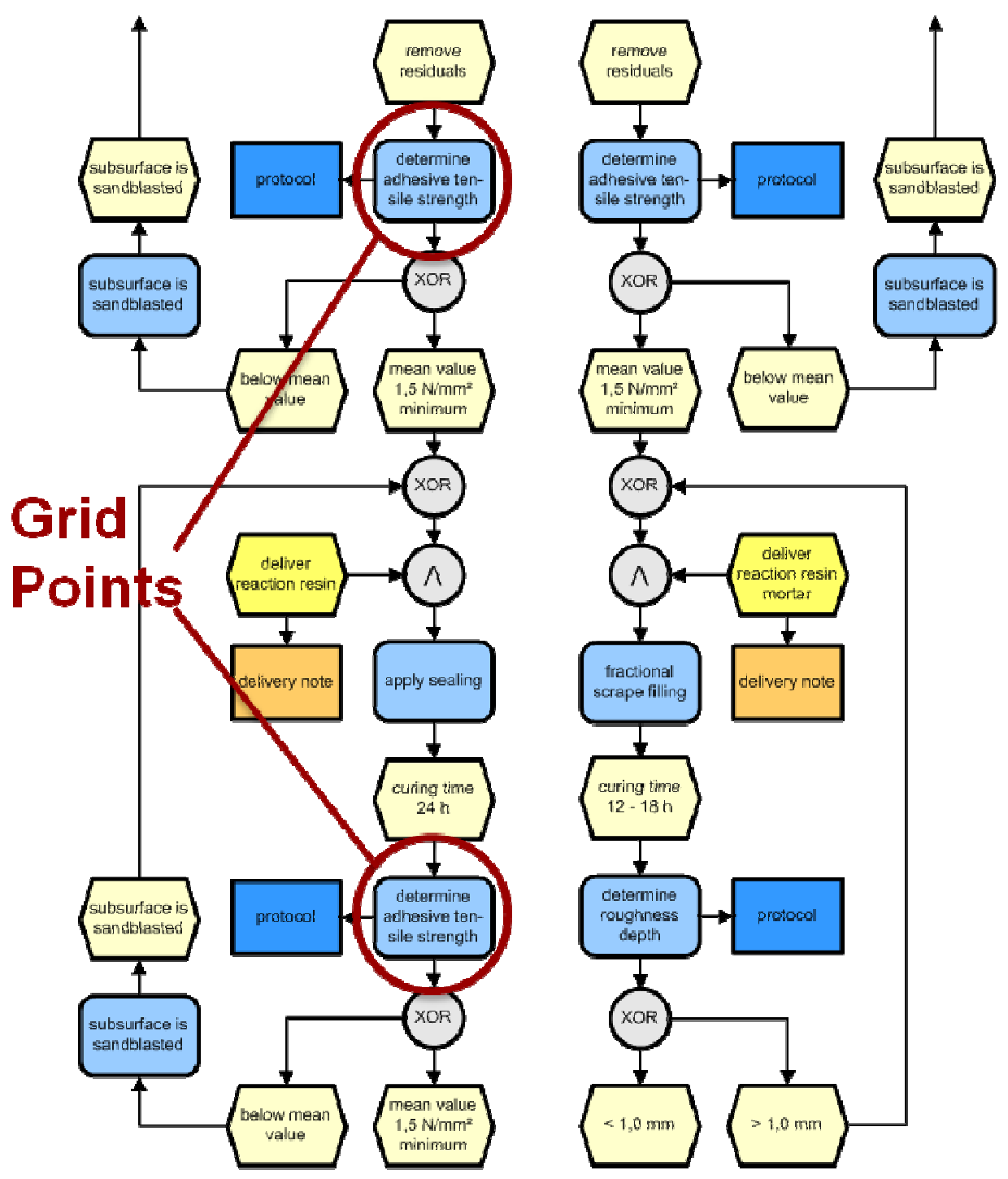

Figure 3: Construction process of a bridge curb

The construction process is structured in horizontal and vertical directions (Buchhop 2007). In the horizontal direction it is structured in terms of main, basic, sub, and manufacturing processes. Furthermore, it is structured in terms of functions, events, and logical and causal dependency relationships. Every function starts with an event, for example a certain activity or a special point in time. These events are identified and described exactly.

The vertical direction defines the degree of detail according to which a process is structured. For example one structural element can be considered as one piece or with all of its single elements. It is defined by the requirements of the simulation. Therefore the processes are structured as detailed as reasonable in order to implement building strategies and to identify realizable corrective actions in case of delays. All documents are taken successively during the building process, where start time and duration is monitored. Furthermore, all documents are attached to process events.

Finally all process times are monitored as durations of activities as well as cycle times for recurrent processes (minimum, maximum, and average). 


\subsection{Evaluation of sub-processes}

During the investigation of a detailed construction process, sub-processes and activities are evaluated in terms of their importance and significance in relation to the aggregated process.

The idea in structuring the building process is to identify "grid points". This term is adopted in analogy to analytical algebra (Figure 4). Using this approach, a curve's shape can be defined if a sufficient number of discrete points and the type of curve are known. In the same way a sufficient amount of reliable process information will be used to define the actual status of work. This information will be taken as grid points for the indication of the actual state of construction progress. Grid points are set up as control gates from which signal information can be generated or taken. They indicate clearly, or at least with reasonable certainty, which events have taken place and which activities are in progress. Therefore, the kind and density of required information is to be determined.

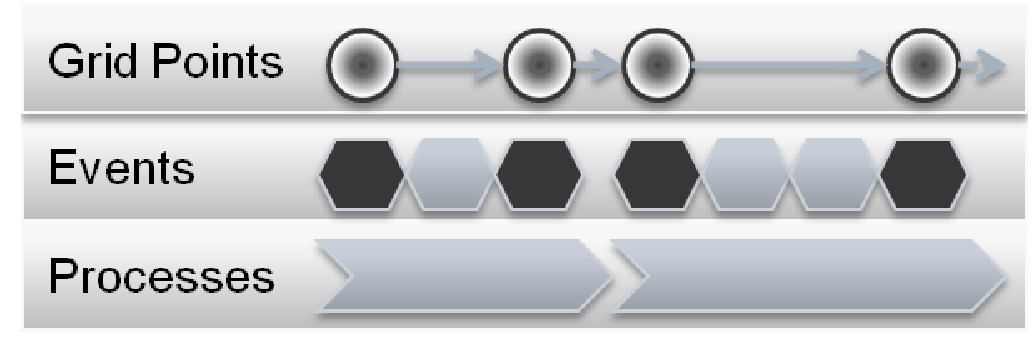

Figure 4: concept of grid points

As already mentioned, each process starts with an event, which can be a certain activity for example. These events have to be identified and described as grid points. Suitable grid points are, for example, events required before a certain procedure can start (material delivery), events assigned to the completion of a procedure (hand over), easy-to-describe intermediate states (finishing of sealing or acceptance of reinforcement), and placement of certain types of rebar and installation units. Grid points are comparable to a less stringent type of milestone in time schedules.

The identification of the most significant sub-processes is important. The AHP (Analytic Hierarchy Process) method is used to rank the processes by the mentioned criteria order to identify key processes, which are of particular importance for the ongoing optimization. Later, these processes are identified by significant events in the construction process. Sensitivity analysis is implemented to check the plausibility of the criteria and their emphasis in the AHP.

The specification of criteria and their scales are only briefly mentioned here due to their complexity. Examples of criteria are kind and number of dependencies to other processes, process duration, required resources, fault liability, error probability, flexibility of execution order and date with respect to parallel processes, and possible correction strategies.

For the criteria, varying scales with values based on deterministic and stochastic concepts are defined. In order to determine those values, different methods will be used. For example, the flexibility of execution order and date will be determined by using the Critical Path Method (CPM), so deterministic values will be calculated. Another example is the process duration. A realistic description of the duration is very important for an appropriate simulation, but it depends very much on the boundary conditions. Therefore stochastic methods as fuzzy logic have to be used. Finally, a sensitivity analysis is implemented to check the plausibility of the criteria and their weighting in the AHP. Beside the identification of significant events, the results will be used for the validation of simulation strategies as mentioned earlier. Next, the grid points have to be connected with the real building process by progress data. 


\section{DATA SOURCES}

In discussing the available data sources, an evaluation of the usable instruments must be done. Up to now most research projects develop and analyze data gathered from one type of source, for example RFID. But the reality in construction varies so much that different techniques of data gathering have to be combined. A suitable mix of these techniques will be established within the ongoing research project. Therefore, different sources of information are identified parallel to the process modeling that in total give significant information about the current state of the construction (Bargstädt 2008).

\subsection{Documents as information sources}

The approach to designing an efficient and realistic controlling tool starts with the identification of documents and other information sources that are widely used on most construction sites. Documents like construction records, minutes of meetings or delivery notes are associated with everyday life on each construction site. Up to this point, they have rarely been evaluated in terms of capturing accurate information about the daily building progress. These documents are analyzed with reference to the information they yield with respect to the degree of completion or material deliveries. Signal information as described above is a matter of particular interest. Furthermore, the common data format is registered, which in many cases is handwriting. Typical information includes:

- $\quad$ deployment/staff data such as number of workers, qualifications, working hours (start/end) and completed work

- $\quad$ machine data such as machine inventory, working hours/place, and quantities completed

- $\quad$ supply data such as shipments

- test results

- $\quad$ acceptance results

- $\quad$ disengaging dates

- $\quad$ concreting times (start/end)

- $\quad$ site measuring quantities

- $\quad$ general output documentation (description of daily output)

- weather data such as temperature, hours of rain, and wind speed

To extract this information, the authors first asked for the documents, which are commonly generated on construction sites. This research was based on the literature and on a nationwide survey addressed to site mangers who work for construction companies of different sizes.

The site documents can be divided into three groups: documentation on a normative basis, on a contractual basis, and for internal controlling issues. These documents are evaluated in terms of the information they provide about the construction progress. The information is assigned to categories as shown in Table 1 . 
Table 1: Information categories

\begin{tabular}{|c|c|c|}
\hline categories & Data type & Definition \\
\hline resources & supply data & Documentation of material entries. \\
\hline capacities & staff data & Documentation of number and qualification of workers. \\
\hline$\stackrel{\downarrow}{\text { production output }}$ & production output & Documentation of number and type of machines. \\
\hline \multirow[t]{2}{*}{ production output } & site measuring data & $\begin{array}{l}\text { Data for billing, documentation of quantities and work } \\
\text { completed. }\end{array}$ \\
\hline & $\begin{array}{l}\text { testing / } \\
\text { disengaging data }\end{array}$ & $\begin{array}{l}\text { Data for technical control, state of completion, and limits } \\
\text { of quality. }\end{array}$ \\
\hline $\begin{array}{l}\text { production } \\
\text { ences }\end{array}$ & $\begin{array}{l}\text { progress documenta- } \\
\text { tion }\end{array}$ & $\begin{array}{l}\text { Keeping evidence. Documents for possible court cases, for } \\
\text { example as correspondence. }\end{array}$ \\
\hline $\begin{array}{l}\text { production condi- } \\
\text { tions }\end{array}$ & weather data & Documentation of production conditions. \\
\hline \multicolumn{3}{|c|}{$\begin{array}{l}\text { By defining and emphasizing different criteria, the documents' significance is evaluated and made com- } \\
\text { parable. The following criteria and objects are defined and emphasized on simple ordinal scales (Table 2). }\end{array}$} \\
\hline & \multicolumn{2}{|c|}{ Table 2: Criteria for document/information evaluation } \\
\hline Criterion & \multicolumn{2}{|c|}{ Explanation } \\
\hline significance & \multicolumn{2}{|c|}{$\begin{array}{l}\text { Answers the general question of whether the information is significant to con- } \\
\text { clude on the status of the building progress. }\end{array}$} \\
\hline \multirow[t]{2}{*}{ reference } & \multicolumn{2}{|c|}{ What can the information refer to? } \\
\hline & \multicolumn{2}{|c|}{$\begin{array}{l}\text { To a specific activity, structural element, working section, or to the construction } \\
\text { site as a whole. }\end{array}$} \\
\hline \multirow[t]{2}{*}{ degree of completion } & \multirow{2}{*}{\multicolumn{2}{|c|}{$\begin{array}{l}\text { To which degree of completion can a conclusion be reached from the informa- } \\
\text { tion provided? } \\
\text { To } 100 \% \text { completion, to accurate progress status, or to predefined intermediate } \\
\text { stages? }\end{array}$}} \\
\hline & & \\
\hline \multirow[t]{2}{*}{ gathering rhythm } & \multirow{2}{*}{\multicolumn{2}{|c|}{$\begin{array}{l}\text { How often is the information taken? } \\
\text { When does the event take place: every day, weekly, monthly, not predictably }\end{array}$}} \\
\hline & & \\
\hline gathering probability & \multicolumn{2}{|c|}{ Is the information reliable? } \\
\hline content type & \multicolumn{2}{|c|}{ Does the document contain factual or explanatory information? } \\
\hline conclusion type & \multicolumn{2}{|c|}{ Is it possible to draw a direct conclusion? } \\
\hline
\end{tabular}

The evaluation is made according to AHP. In a subsequent step its applicability for digitization and automation is discussed. (Figure 5)

As expected, all kinds of testing protocols have a high significance with regard to the identification of construction progress. Additional staff and machine data can be used for plausibility control, since this information must be combined with further facts for a reliable conclusion to the construction progress.

Data pooling based on the above-mentioned information sources does not yet describe the building process as accurately as needed. On one hand it is handwritten and often biased; on the other hand it is not yet sufficient for a complete picture of the construction status. Depending on the intended optimization, further information must be captured. Therefore, more sophisticated instruments for data evaluation are considered. It must also be kept in mind that additional information sources should not be based on personal observation and should be protected from errors and bias. 


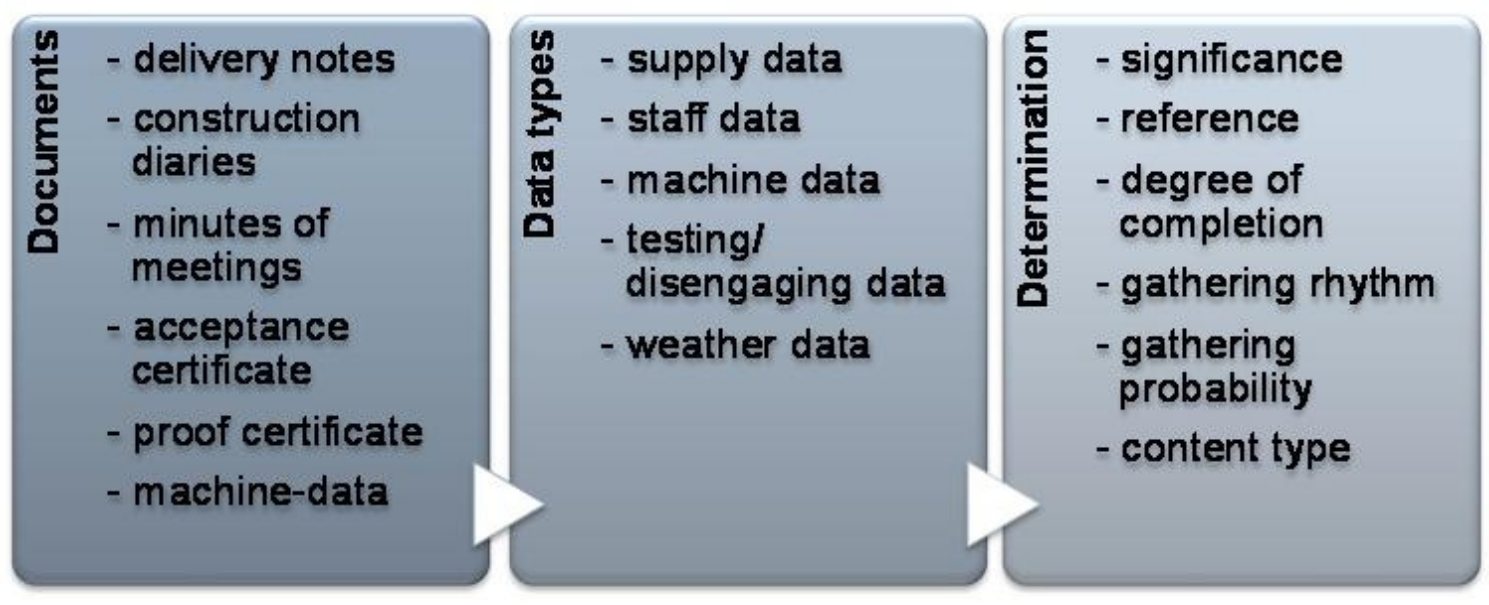

Figure 5: Evaluation of documents

\subsection{Instruments for data evaluation}

Current technical instruments include RFID (Ergen 2007), GPS, Photogrammetric, Laser scanning, Tachymetry and Bar codes (Chen 2002). In all of these fields further improvements will be realized soon. As a result of developments in most technologies it is possible to push the boundaries that were limiting the applications of these technologies to construction just a few years ago. An example is RFID technology, where the size of a RFID chip has become one-tenth of its original size within 5 years, and the price has dropped to $1 / 100$ of the original.

Furthermore, increasingly powerful screening machines create new possibilities for improved application. For example the storage capacity of Photogrammetric increased enormously, and it is possible to exploit many more data points in less time. It even seems realistic that real-time feedback will be possible in the near future (Kutterer 2006).

In addition to these developments, the exchange and storage of data via the internet has created new possibilities. Today it is possible to transfer huge amounts of data to any place in the world, to process them in a central location, and to transfer them back to site. The task is to identify the relevant evaluation instruments and register and analyze them with regard to their ability to record real-time data. This comprises speed, data volume, precision, and automation of data. It leads to the question, which instruments are appropriate to recognize parameters relevant for the building progress. Similar to the document evaluation, constraints and requirements needed for the application of different instruments are considered. Significant parameters are functionality, type of information, degree of automation and type of equipment.

Based on the above analysis, the different information sources and instruments are methodically compared to one another and interpreted with regard to a specific subsequent processing within the system for capturing the real-time state of construction.

The possible information sources and instruments are evaluated with regard to the construction process to be controlled. They are systematized and tested on their ability to capture signal information at grid points, both as single sources and when combined with other types of sources. In addition, a catalogue of typical construction elements is developed, which will answer the question of how to capture different kinds of elements best.

The instruments are compared based on multiple criteria including reliability (subjective or objective), quality, flexibility, workability, complexity, comparability with standard values, etc. 


\section{COMBINING PROCESS MODELING AND DATA EVALUATION}

The basics developed so far concerning process modeling and data evaluation will then be combined into one model. By using process modeling, the building progress is structured in events, functions, relations, and additional grid points pursuant to the requirements of deadline monitoring and simulation. Therefore it defines where and when information should be captured.

Those points will be matched with the possible data sets as shown in Figure 6. Preference is given to real-time data. In the first step the model will be fed with data that are taken according to availability and actuality (information sources). These data are in any case reviewed with regard to their relevance and their ability to describe the status at a considered grid point. Data with less relevance will be held back for further usability, for example checking on the plausibility.

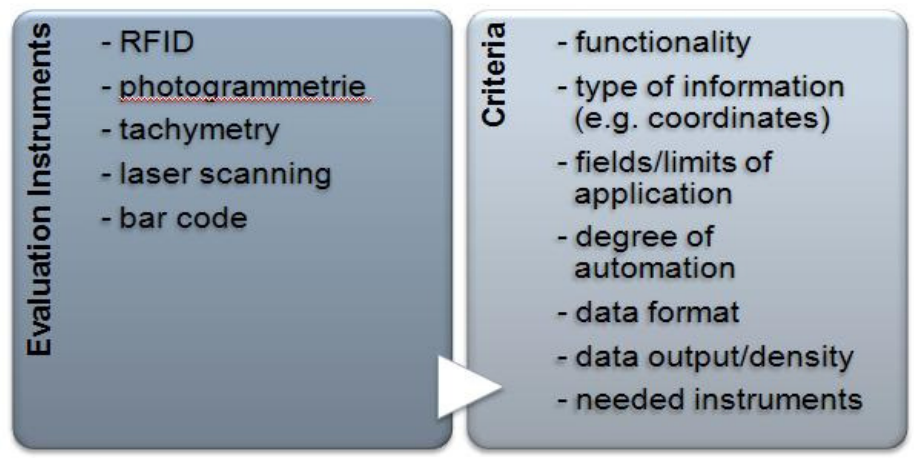

Figure 6: Evaluation of Instruments

Such monitored and in some main elements generated virtual models of the building process may still be incomplete. Therefore further appropriate instruments for data evaluation will be selected and activated in order to complete the monitored situation. They will supply the monitored model with sufficient information for the remaining grid points. This supplementary data gathering is taken by means, which are chosen based on the above-mentioned multi-criteria comparison.

Using a sample construction process as a test environment, a complete simulation model with different data evaluation and grid points is developed. On this model, tests are run with regard to data formats, evaluation intervals, and response times. An important aspect is the fast and integrated data handling, which allows daily steering. In everyday construction business, this time relation is of particular importance for an accurate daily simulation. Of course, the automatic generation and evaluation of the data is one special aspect. Another important aspect is to make use of combinations of data and of redundancies for plausibility checks. At the same time redundant information may also detect contradictory data, which calls for special algorithms to distinguish between true and false data. The individual adjustment of the different information sources and instruments is essential for the efficiency of the whole monitoring system.

\section{CONSTRUCTION METHODS AND DESCRIPTION OF COMPLEX PROCESSES}

Results from the simulation experiments have to be verified on several projects. The translation to a bigger project like a bridge superstructure with more information has to be done with consideration for gathering and evaluation of data. It has to bear in mind that even different construction methods will have an impact as well. The individual adjustment of the different information sources and instruments is essential for the efficiency of the whole monitoring system. An open information standard can help to support this. This suggests complete control of the construction process, but a construction is very complex for detail modeling. Better information sources as base for process modeling and data evaluation is necessary for steering processes. To analyze the combining of process modeling and data evaluation for complex 


\section{Ailland, Bargstädt and Hollermann}

processes like bridge superstructure and compare them with the simulation and smaller projects is necessary. A tool box with different models for building processes will be created.

\section{CONCLUSION / PERSPECTIVES}

One objective of this research is to evaluate applications and limits of the presented concept using grid points. A further aspect is the question of how the evaluated data can be implemented in a simulation tool. Using simulation in construction processes that have been developed at the Chair of Construction Engineering and Management at Bauhaus-University Weimar (Beißert et al, 2007), the prototype implementation of different instruments for data generation is added to the simulation model. The effects of different performances then will be analyzed.

Simulation models are suitable for developing construction sequences, as shown in (König, 2007). This approach considers the monitoring aspects of construction sites. Data gathering, data processing, and the following steering processes are implemented in the simulation model. It yields information about the importance of precision, velocity, automation, redundancy, and significance of data capturing during construction processes. The results, advantages, disadvantages, weak points, and application limits can be adjusted for different construction conditions. Furthermore, the error-proneness can be tested. One important aspect of this will be missing data and how the simulation will react in the case of uncertainties or, for example, a missing delivery note.

With the knowledge gained from these simulation experiments, the results will be verified on a prototype and translated to a more complex process like a bridge superstructure. Even if the model suggests complete control of the construction process, the reader should be aware that construction is far too complex to rely simply on automation. The presented approach is a way to improve the information on ongoing construction sites. Data gathering, data processing, and the following steering processes will be supplemented with costs. It will enable the construction manager to better concentrate on real obstacles that have not been encountered in advance, and to have better information for routine processes to be steered. In this way the time to react will be shortened. It is then also possible to evaluate effective counteractions by using the simulation tool fed in with current real-time data gathering.

\section{REFERENCES}

Bargstädt H.-J. and K. Ailland. 2008. Capturing the real time state of construction for simulation, IABSE Conference, Helsinki, Finland, Conf. Proceedings.

Bayer J. 2003. Simulation in der Automobilproduktion, Springer, Berlin.

Beißert U., M. König, D. Steinhauer, and H-J. Bargstädt. 2007. Constraint-Based Simulation of Outfitting Processes in Shipbuilding and Civil Engineering, 6th EUROSIM Congress on Modelling and Simulation, Conf. Proceedings, Ljubljana, Slovenia.

Buchhop E. 2007. Zeitliche Erfassung von Kernprozessen als Teil der Prozessanalyse, bdvb-Award Geschäftsprozess- und Projektmanagement, CT Salzwasser-Verlag, Bremen.

Bundesministerium für Verkehr, Bau- und Wohnungswesen. 2004. Richtzeichnungen für Ingenieurbauten, Verkehrsblatt-Verlag, Dortmund.

Chen Z., H. Li and C.TC. Wong 2002. An application of bar-code system for reducing construction wastes,

Automation in Construction, Vol. 11, no. 5, pp. 521-533.

Ergen E., B. Akinci, and R. Sacks. 2007. Tracking and locating components in a precast storage yard utilizing radio frequency identification technology and GPS, Automation in construction, Vol. 16, pp. 354-367, 25.07.2006.

Hohmann G. 1997. Von der Netzplantechnik zur Simulation - Analyse von Bauprozessen mit Hilfe von Petri-Netzen. Internationales Kolloquium über Anwendungen der Informatik und Mathematik in Architektur und Bauwesen, IKM , 14 , 1997 , Bauhaus-Universität Weimar, Germany. 


\section{Ailland, Bargstädt and Hollermann}

König M., U. Beißert, and H-J. Bargstädt. 2007. Constraint-Based Simulation of Outfitting Processes in Building Engineering, 24th W78 Conference, Conf. Proceedings pp.491-497, Maribor, Slovenia.

Kutterer H. and C. Hesse. 2006. High-speed laser scanning for near real-time monitoring of structural deformations, Tregoning, P., Rizos, R. (Eds.): Dynamic Planet - Monitoring and Understanding a Dynamic Planet with Geodetic and Oceanographic Tools, IAG Symposia, Vol. 130, Springer, 776 781.

Tecnomatix. 2006. Tecnomatix Plant Simulation, Step-by-step Help, Handbook Version 8.1., Stuttgart.

\section{AUTHOR BIOGRAPHIES}

KARIN AILLAND is a civil engineer. During the last 9 years she worked on several occupational fields of civil engineering, most of the time in consulting offices for railway construction and bridge building. In 2006 she returned to the university to do research at the chair of construction engineering and management at the Bauhaus-University in Weimar.

She is working for her doctoral degree in Civil and Structural Engineering in the field of process modelling and simulation. The objective of the dissertation is to capture the building progress on infrastructure construction sites daily accurate in order to create a real-time progress model for process simulation. The intention is to improve the deadline monitoring on constructions site by using the great potential of simulation that arises from identifying long-term consequences at earlier stages. Therewith the controlling and flexibility in case of changed conditions will increase enormously. Her email address is $<\mathrm{Ka}-$ rin.aillandeuni-weimar.de>

HANS-JOACHIM BARGSTAEDT is Professor for Construction Engineering and Management at the Bauhaus-University Weimar. He studied in Braunschweig, Atlanta and Marseille. He got his Ph. D. from the Technical University Braunschweig in 1988.

He worked 3 years in structural engineering offices. After his $\mathrm{Ph}$. $\mathrm{D}$. he worked more than 10 years for an international construction company. There he was responsible site engineer, site manager and project manager for several projects. As branch manager and director of a branch office he managed many different projects as dry docks, harbor construction and bridges as well as hotel and office buildings, and construction in the built environment.

Since 2000 he is Professor at the Bauhaus-University Weimar. His research fields are construction processes, construction management, simulation in construction, construction in the built environment and lifecycle considerations. E-mail is <hans-joachim.bargstaedteuni-weimar.de>

SEBASTIAN HOLLERMANN is an civil engineer in the Department of Building Operations and Building Processes, Bauhaus-University Weimar. He is doing his dissertation on the chair of construction engineering and management at the Bauhaus-University in Weimar. Before moving to academia, he accumulated over several years of construction site management experience for bridges at Bilfinger Berger Ingenieurbau GmbH, Scandinavian Branch, Göteborg, Sweden, Awarding authority for bridges with subsidence caused by mining, Water and Shipping Administration of the Federal Republic of Germany, Hamm, Germany. He received an engineering degree from the University of Applied Sciences Münster, Germany, a Scholarship of German National Academic Foundation, a journeyman's certificate of the Chamber of Crafts, Vechta, Germany, a research grant of the German Academic Exchange Service for a research about shear connectors for timber concrete composite bridge constructions, Joensuu, Finland.

His research interests are in construction process simulation of concrete bridge superstructure building based on significant day-to-day data including costs. His email address is <sebastian.hollermann@uni-weimar.de> 